\title{
Ki Enthus Susmono: Skandal Performatif Don Juan dan Kebaruan Gagrag Pedalangan
}

\author{
Hariyanto \\ Magister Ilmu Religi dan Budaya, Universitas Sanata Dharma Yogyakarta \\ Email: abimanyuhariyanto@gmail.com
}

\begin{abstract}
This article analyzes Ki Enthus Susmono's performance through observing some of his previous performances, with the performance idea of Shoshana Felman (2003) in his book, The Scandal of Speaking Body: Don Juan with J.L. Austin, or Seduction in Two Languages, which reads the Don Juan theater by Molière. As a result, it was found that there were similarities between promises by J.L. Austin, Don Juan and Ki Enthus Susmono. Ki Enthus Susmono's performance has been successfully built through the eclectic, parody and irony representation of postmodern art, which shows the reality of his body's actions, has been produced repeatedly to produce certain effects so that it becomes a habit (myth). Through his performativity, Ki Enthus Susmono showed his success in building a novel marker of gagrag puppetry.
\end{abstract}

Keywords: Ki Enthus Susmono; gagrag Tegalan; performativity; postmodern art; promise action; speaking body; novelty

\begin{abstract}
Abstrak
Artikel ini menganalisis performativitas Ki Enthus Susmono melalui pengamatan beberapa rekaman pertunjukannya terdahulu, dengan gagasan performativitas Shoshana Felman (2003) dalam bukunya, The Scandal of The Speaking Body: Don Juan with J.L. Austin, or Seduction in Two Languages, yang membaca teater Don Juan karya Molière. Hasilnya, ditemukan bahwa ada kesamaan antara tindakan janji oleh J.L. Austin, Don Juan dan Ki Enthus Susmono. Performativitas Ki Enthus Susmono berhasil dibangun melalui strategi representasi seni postmodern yang eklektis, parodi, dan ironi, yang menunjukkan realitas tindakan tubuhnya, telah diproduksi berulangkali untuk menghasilkan efek tertentu sehingga menjadi kebiasaan (mitos). Melalui performativitasnya tersebut, Ki Enthus Susmono menunjukkan keberhasilannya membangun penanda kebaruan gagrag pedalangan.

Kata kunci: Ki Enthus Susmono; gagrag Tegalan; performativitas; seni postmodern; tindakan janji; speaking body; kebaruan
\end{abstract}

\section{Pendahuluan}

Penelitian ini bermula dari pengamatan langsung di lapangan ketika menonton pertunjukan "Pergelaran Wayang Golek Cepak Tegal Lakon
Kembang Wijaya Kusuma” (selanjutnya disebut WGGT), dalam rangka penutupan Hari Wayang Dunia II di Pendapa Ageng Joyokusumo ISI Surakarta pada 8 November 2016 lalu. Selang sehari kemudian, saya juga berkesempatan melihat 
pembukaan pameran boneka wayang karya $\mathrm{Ki}$ Enthus Susmono, Enthussiasm, di Galeri Katamsi ISI Yogyakarta pada 9 November 2016. Pada dua kesempatan tersebut, Ki Enthus Susmono juga mempublikasikan dua buah buku karyanya. Buku pertama berjudul, Wayang Gagrak Tegal (2016) berisi deskripsi mengenai identitas wayang Tegal yang dirunut secara historis melalui keterangan beberapa studi pustaka terdahulu. Sementara buku kedua yang berjudul, Pakeliran Wayang Gagrak Tegal, Jati Kusuma (2016), berisi panduan dan tata cara (caking pakeliran) mementaskan Wayang Gagrak Tegal dengan Lakon Jati Kusuma, meliputi narasi, suluk, maupun notasi balungan iringan karawitannya.

Dari hasil pengamatan dua peristiwa tersebut, dapat disimpulkan bahwa pertunjukan WGGT pada 8 November 2016 tersebut adalah pertunjukan hibridis (campuran). Fenomena pertunjukan hibridis dalam WGGT tersebut menjadi paradoks dengan klaim Ki Enthus Susmono mengenai "keaslian" gagrag Tegalan yang diusungnya, seturut dengan dua buah buku karya yang dipublikasikan. Pada kedua kesempatan tersebut, ia juga mengungkapkan kekecewaan mengenai anggapan remeh masyarakat atas fenomena kebudayaan pesisir Pantura, khususnya Tegal. Ia menduga, budaya Tegal telah ditidurkan secara politis oleh penguasa terdahulu. Kemudian sebagai poin penting selanjutnya adalah, adanya ajakan, tantangan, dan janji yang diungkapkan Ki Enthus Susmono untuk menggunakan gagrag Tegalan, bersaing dengan gagrag lain di Nusantara.

Setelah mengamati dan membuat catatan atas dua peristiwa tersebut, saya kemudian melihat kembali perjalanan Ki Enthus Susmono. Ia mulai dikenal masyarakat pedalangan dan khalayak sejak era 1990-an sebagai dalang yang memiliki kekhasan gaya pertunjukan yang kontroversial dan distigmakan oleh kalangan pedalangan konservatif sebagai dalang édan yang nakal dan menabrak atau merusak "pakem" pedalangan. Namun demikian, stigma itu juga diikuti dengan tanggapan pujian oleh beberapa pihak, seperti Emerson (2016) dan Boonstra (2014), yang terkesan dan menganggap Ki Enthus Susmono sebagai dalang jenius, inovatif, serta kreatif. Puncak karirnya ditandai ketika ia kemudian naik ke panggung politik dan berhasil menjadi Bupati Tegal terpilih periode 2013-2018.
Namun pada 14 Mei 2018, Ki Enthus Susmono meninggal dunia meninggalkan kesedihan dan kesan mendalam di hati banyak pecinta wayang dan seni pedalangan.

Fenomena atas gaya panggung dan kiprah $\mathrm{Ki}$ Enthus Susmono, klaim "keaslian" gagrag Tegalan yang paradoks dengan gaya sajian yang dibawakan dalam $W G G T$, dibaca dalam perspektif kajian budaya, melalui payung performance studies. Analisis performativitas penelitian ini merujuk gagasan Shoshana Felman (2003) dalam bukunya, The Scandal of The Speaking Body: Don Juan with J.L. Austin, or Seduction in Two Languages, yang didukung dengan teori seni postmodern oleh Nigel Wheale (1995). Objek material penelitian adalah pengamatan pertunjukan langsung dan beberapa rekaman pertunjukan Ki Enthus Susmono yang telah diunggah oleh beberapa channel youtube, baik wayang kulit, wayang santri, maupun WGGT, dengan data rekaman mulai dari 1997 hingga 2018.

\section{Performativitas Ki Enthus Susmono}

Sebelum membahas mengenai performativitas Ki Enthus Susmono, maka saya kembali melihat apa yang Schechner (2013) katakan dari beberapa pendapat yang ia sarikan mengenai performativitas, yang dibagi dalam dua hal. Pertama, performativitas dalam wilayah kebahasaan, dalam hal ini merujuk pada teori tindak tutur: tindakan performatif, berada pada wilayah ujaran seperti dalam contoh janji, taruhan, atau rayuan. Wilayah kedua, performativitas adalah konsep atau ide di balik suatu pertunjukan atau tindakan, atau sebuah aktifitas. Ia menggunkan analogi "as if" seperti yang digunakan dalam dunia teater, yang terdiri dari karakterisasi, tempat, akting, narasi, dan seluruh aspek yang dipertunjukkan dalam permainan.

Pada level selanjutnya, "as if" dikaitkan dengan konstruksi realitas sosial, seperti gender, ras, atau apapun yang diasumsikan sebagai hasil sebuah konstruksi. Pada level yang lain, performativitas adalah irisan mengenai mood dan rasa, baik itu visual maupun non visual namun dalam kapasitas yang dipertunjukkan, sehingga memunculkan suatu tanggapan atau ketertarikan pihak lain yang melibatkan pengalaman inderawi rasa: ketertarikan yang telah dilihat, didengar, dirasakan dari sebuah fenomena pertunjukan. Schechner (2013:168-169) 
memberikan contoh beberapa kalimat tanggapan seperti: "I smell something funny going on," (saya mencium sesuatu yang lucu sedang terjadi) atau "that's to my taste," (itu seperti cita rasa saya) atau "I was touched by what happened" (saya tersentuh dengan apa yang telah terjadi tadi). Ketiga kalimat tersebut dapat digunakan sebagai pendekatan untuk memahami performativitas.

Lain halnya dengan Richard Schechner (2013), Shoshana Felman (2003) dalam bukunya, The Scandal of The Speaking Body: Don Juan with J.L. Austin, or Seduction in Two Languages, memiliki gagasan yang mengkritisi sekaligus melengkapi teori tindak tutur Austin yang menarik, karena menggunakan pendekatan teori kebahasan-dekonstruksi dan psikoanalisa Lacanian. Berbeda dengan Derrida (1988) dalam tulisannya, Signature, Event, Context yang mengkritisi tindak tutur Austin menggunakan dekonstruksinya dalam fungsi penulisan, bukan ucapan, bahwa: jika kehadiran subjek menawarkan keabsahan efek, menunjukkan bahwa kata yang diucapkan memiliki kekuatan performatif harus tunduk pada logika iterabilitas (kemampuan suatu teks untuk selalu dimaknai terus menerus dalam konteks yang berbeda-beda) yang membutuhkan transposabilitas dari kata yang tertulis; maka Felman berusaha mengembalikan kritik tindak tutur Austin pada wilayah suara dan ujaran (tuturan).

Felman (2003) melihat adanya celah atas keambiguan yang ditimbulkan teori tindak tutur Austin. Ia menggunakan psikoanalisa Lacanian untuk mengisi ruang keambiguan Austin dengan menjawab pertanyaan what was Austin saying, dengan dua jawaban, what Austin was doing with what he was saying. Pertanyaan ini berfokus pada aspek performatif atas teori tuturan performatif, yang menggaris bawahi pengulangan dan status data referensial diri (selfreferensial) dari teori tindak tutur sebagai pusat konsep performativitas. Dua kajian mengenai performativitas yang senada dengan gagasan Felman ialah kajian mengenai performativitas oleh Sarah Claeys (2007: 6-20) dalam disertasinya berjudul: "How To Do Things With Butler: An Inquiry on The Origin, Citation and Application of Judith Butler's Theory of Performativity" juga dalam artikel yang ditulis oleh Ana Vulic (2012) dalam Jur nal Forum: University of Edinburgh Postgraduate Journal of Culture and the Arts, berjudul: From a Misfire to an Open Future: Repetition, Performativity, and The Promise of The Metaphor. Gagasan Felman dihasilkan atas studinya membaca mitos Don Juan dalam teater oleh Molière, menelaah janji (promise) dan rayuan (seduction).

Berdasarkan paparan atas pendapat Felman di atas, dapat disarikan bahwa performativitas terletak pada gagasan pengulangan atas tindakan tubuh yang menghasilkan efek ilusi berulang-ulang, sehingga tindakan berulang tersebut menghasilkan efek mitos (kekhasan) daya seseorang. Dalam penelitian ini, seperti telah dipaparkan di muka, Ki Enthus Susmono adalah mitos dalang kontroversial dengan stigma "èdan" di dunia seni pedalangan Indonesia. Ia dikenal sebagai dalang gagrag campuran yang memiliki kekuatan verbal serta permainan visual menonjol yang berani menggunakan permainan bahasa, pisuhan atau umpatan (Poerwodarminto, 1939: 434) jorok, tabu, kasar, namun berhasil memukau banyak orang. Upaya itu dilakukan sebagai proses melakukan pencarian dan menyuarakan kebaruan gagrag, sebagai ekspresi kritisnya terhadap legitimasi gaya-gaya istanasentris pada dua gagrag besar keraton Jawa, Surakarta dan Yogyakarta, sebagaimana dibahas oleh Pemberton (2003).

Kebosanan (penolakan) Ki Enthus Susmono pada (tekanan) pakem pedalangan tradisi istanasentris dua gagrag besar tersebut, ia kritisi dengan upaya pencarian yang melahirkan wacana kebaruan. Di antaranya membuat dan membangun penanda-penanda baru dengan cara bermainmain dan memain-mainkan idiom-idiom tradisi, mempertemukannya dengan idiom lain di luar pakem tradisi dua gagrag besar, mencampur dan mengkombinasikannya sebagai penanda kebaruan. Idiom-idiom itu meliputi: bentuk wayang, gaya, dan model sunggingan wayang, tata panggung yang meliputi penataan instrumen orkestrasi gamelan, gaya musikal iringan, kelir, kostum dalang dan pengrawit, bahkan tata cara mendalang (caking pakeliran) yang kemudian dapat dikatakan menjadi penanda kebaruan gagrag. Penanda inilah yang kemudian ketika berhadapan dengan klaim keadiluhungan yang dilegitimasi dari gagrag dua keraton besar Jawa, menimbulkan tanggapan kontroversial. Ki Enthus Susmono menjadi besar dan terkenal karena konsistensinya menggarap penanda kebaruan, sebagai kebaruan gagrag yang terus menerus kontroversial. 
Kontroversi Ki Enthus Susmono bahkan terus berlangsung hingga menjelang akhir karirnya sebagai dalang sekaligus Bupati Tegal periode 20132018, ditandai dengan publikasinya pada khalayak dan masyarakat dunia pedalangan mengenai (klaim) gagrag Tegalan, dalam pertunjukan: Wayang Golek Gagrag Tegalan (WGGT), dan kedua bukunya mengenai, Wayang Gagrak Tegal (2016). Apa yang dilakukannya dengan (klaim) "keaslian" gagrag Tegal, melahirkan kontroversi baru di kalangan seniman dan dunia pedalangan. Salah satunya penolakan Ki Gunawan Suwati dari Slawi, seperti yang dituliskan dalam buku Sumarsam (2018). Kontroversi itu lahir karena ambiguitas gagrag Tegal yang digaungkan Ki Enthus Susmono, di mana dapat dijumpai paradoks-paradoks antara tulisan dalam kedua buku yang ia tulis, dengan karya pertunjukan yang ia publikasikan. Dalam tulisan di kedua bukunya, ia menuliskan (klaim) keaslian gagrag Tegal dengan bentuk dan model tradisi (dibaca sebagai pakem). Namun demikian pada praktiknya, salah satunya pada pertunjukan WGGT di ISI Surakarta 8 November 2016, Ki Enthus Susmono menampilkan gaya personalnya seperti dalam karya-karya sebelumnya yang sangat kental dengan kegilaannya: bentuk-bentuk hibridis atau campuran, serta caking pakeliran yang extraordinary.

Ambiguitas Ki Enthus Susmono dan bentuk hibridis yang selalu ditawarkan sebagai ciri khas gagrag pedalangannya, akan dibaca sebagai penanda kebaruan dalam performativitas Ki Enthus Susmono. Sebagaimana dikatakan Schechner (2013: 129) dalam bukunya, Performance Studies, performativitas terkait atau terhubung dengan postmodernisme. Berdasarkan itulah pada sub bagian selanjutnya akan berfokus untuk membaca bentuk-bentuk hibridis dan tindakan ngédan yang dilakukan Ki Enthus Susmono dalam membangun kebaruan gagrag, yang dianalisis dengan teori seni postmodern Nigel Wheale (1995), dalam The Postmodern Arts: an introductory reader. Bentukbentuk eklektisme, ironi, parodi, dan lainnya akan diperlihatkan dari unsur pertunjukan yang dibawakan Ki Enthus Susmono, seperti dalam hal penggunaan boneka wayang, iringan, dan garap musikal, dhagelan-guyonan atau humor, serta perilaku ngédan dalang lainnya di atas panggung.
Setelah analisis dengan melihat bentukbentuk dalam strategi representasi seni postmodern, performativitas Ki Enthus Susmono juga dibaca dan dianalisis dengan gagasan Shoshana Felman (2003) dalam The Scandal of The Speaking Body.

\section{Strategi Representasi Seni Postmodern}

Postmodern dimaksudkan sebagai upaya-upaya untuk terus membuat kritik atas ketidakpuasan pada pemikiran-pemikiran gambaran dunia dan epistemologi serta ideologi modern. Pengertian ini disarikan dari tulisan Bambang Sugiharto (2017: 24-32) dalam Postmodernisme dan Tantangan Bagi Filsafat. Selanjutnya, dalam ranah seni, postmodernisme ditujukan sebagai gerakan untuk menunjukkan mandegnya birokrasi museum dan akademi. Di antaranya melalui upaya-upaya dengan mengasosiasikan: hilangnya batas antara dunia seni dan kehidupan sehari-hari, merobohkan bangunan yang membatasi antara budaya tinggi dan budaya pop, pencampuradukan yang bersifat eklektik, parodi, pastiche, ironi, bermain-main dengan budaya "permukaan", tanpa peduli "kedalaman". Dapat pula dikatakan bahwa postmodern berarti bermain-main dengan tanda, sebagai cara untuk merobohkan kemapanan yang telah dianggap sebagian kalangan sebagai kebenaran mutlak, sehingga kemudian melahirkan sebuah realitas yang tidak statis. Keterangan tersebut seperti yang dibahas oleh Nigel Wheale (1995: 33-64), dalam bukunya berjudul The Postmodern Arts: an introductory reader.

Wheale (1995: 42) dalam tulisannya mengatakan, dalam seni postmodern dapat dimungkinkan penggunaan strategi dalam bentuk-bentuk eklektisme untuk menghasilkan parodi dan ironi, namun dapat pula menunjukkan cita rasa schlock, kitsch, camp, atau strategi yang bersifat alegori dan self reflexive. Eklektisme dapat diartikan sebagai penggabungan, kombinasi, campuran berbagai elemen budaya. Dalam praktiknya, eklektisme mengambil beberapa elemen dari budaya berbeda, dikombinasikan dalam satu formula bentuk. Sementara parodi dapat ditunjukkan dengan praktik reproduksi bentuk semula, namun dimainkan untuk tujuan tertentu. Barangkali dalam istilah Jawa lazim disebut sebagai plèsètan. Sedangkan ironi berarti mengatakan suatu hal, 
dengan cara menyiratkan kebalikannya melalui sarkasme atau ejekan.

Dengan melihat tiga strategi representasi seni postmodern: eklektis, parodi, dan ironi saja akan banyak ditemui dalam setiap pertunjukan wayang oleh Ki Enthus Susmono. Ketiga strategi sebagai representasi seni postmodern tersebut dapat dijumpai sejak awal hingga akhir pada keseluruhan elemen pertunjukan, mulai dari visual dan verbal serta aspek pendengaran melalui caking pakeliran: iringan, suluk, dan penceritaan adegan. Bentuk eklektisme yang berpadu dengan parodi dan ironi, dapat dijumpai di seluruh pertunjukan Ki Enthus Susmono baik wayang kulit, maupun wayang golek. Di antaranya seperti dalam pertunjukan WGGT yang dilangsungkan di ISI Surakarta pada 8 November 2016 lalu.

Pada pertunjukan WGGT lakon Kembang Wijaya Kusuma di ISI Surakarta tersebut, dari sisi depan penonton bagaimana panggung sebagai arena dalang terlihat dengan tampilan simpingan wayang cepak terbentang panjang hampir sekitar 13 meter, seperti ketika menyaksikan pertunjukan wayang kulit era sekarang yang menggunakan kemasan megah, terkesan elit, dengan panjang gawangan kelir dan simpingan wayang 12-13 meter. Gawangan kelir berikut simpingan sepanjang itu, lazim dijumpai ketika menyaksikan pertunjukan dalang-dalang besar kenamaan seperti Ki Manteb Soedarsono, Ki Anom Suroto, Ki Purbo Asmoro, begitu juga seperti koleksi Kondang Sutrisno (Ketua Pepadi Pusat sekarang) pemilik Sanggar Putra Pendawa Bekasi. Ki Enthus Susmono pada pertunjukan WGGT di Pendapa Ageng Joyokusumo ISI Surakarta sepertinya menggunakan konsep yang sama, agar terkesan megah, elit, dan elegan.

Jagatan wayang golek sebagai arena permainan dalang berikut simpingan wayang golek cepak sepanjang hampir 13 meter tersebut diwarnai dengan pemandangan lain yang berbeda. Jika pada pertunjukan dan tata panggungan wayang golek purwa Sunda tidak lazim menggunakan pembatas simpingan dan jagatan sebagai arena mobilitas wayang dalam permainan menggunakan kayon, $\mathrm{Ki}$ Enthus Susmono justru menggunakannya hingga empat buah. Masing-masing kayon terdiri dari dua berukuran besar dan dua berukuran sedang yang ditancapkan di kanan-kiri jagatan. Belum selesai dengan itu, dapat nampak dengan sangat kentara dan mengintimidasi penglihatan penonton, yakni penggunaan pembatas jagatan di kiri dan kanan berbentuk masing-masing setengah bagian kayon berukuran besar dengan tinggi sekitar 2 meter. Pembatas ini barangkali dapat dibayangkan seperti halnya pembatas-pembatas tonil di panggung kethoprak yang terpasang di kanan dan kiri panggung.

Boneka wayang yang digunakan untuk mendalang membawakan lakon, terdiri dari boneka wayang cepak yang sudah dimodifikasi, seperti diperbesarnya ukuran yang semula kecil menjadi seukuran wayang golek sunda, kemudian modifikasi bentuk persendian tangan dan bahu menjadi bentuk tumpul atau bulat di ujung lengan atas, sehingga memungkinkan gerak tangan yang lebih leluasa: dapat menyamping 180 derajat. Selain itu, dijumpai pula beberapa pola gerak wayang golek, seperti wayang golek Menak dan wayang golek purwa Sunda. Pola gerak khusus khas wayang golek Menak terdiri dari ongkèk, ulap-ulap, seblak sampur, dan tanjak, sebagaimana dipaparkan oleh Sukistono (2013: 190). Sementara untuk pola gerak wayang golek Purwa Sunda yang dimaksud di sini adalah gerakan-gerakan khusus yang seringkali digunakan dalam pola gerakan tarian seperti gedig, keupat, galieur, dan godeg (Cahya, 2014: 149).

$\mathrm{Ki}$ Enthus Susmono juga menggunakan wayang golek Purwa Sunda seperti: boneka-boneka wayang buta (raksasa), Cepot Astrajingga dengan salah satu kaki diperlihatkan dan dapat digerakkan untuk adegan menari jaipong, serta boneka penari Endhèl dengan leher dan kepala yang dapat digoyangkan. Selain itu, ia juga menggunakan kayon ciptaannya seperti kayon mesjid, serta menggunakan wayang berbentuk pepohonan yang lazim digunakan dalam pertunjukan wayang kancil. Dalam hal penggunaan pepohonan ini, Ki Enthus Susmonolah yang rupa-rupanya mempopulerkan penggunaannya pada pertunjukan wayang purwa, dengan berbagai modifikasi bentuk yang ia lakukan.

Instrumen gamelan yang digunakan selain gamelan Jawa berlaras sléndro, juga ditambahkan seperangkat gamelan Bali (Gambelan Kebyar), kendang wayang golek Sunda, simbal dan bass drum. Berbeda dengan WGGT di ISI Surakarta, untuk wayang santri $\mathrm{Ki}$ Enthus Susmono cenderung menggunakan instrumen minimalis. Yakni dengan satu atau dua buah demung, dua 
buah saron, jengglong, gong besar, kendang Sunda, bass drum dan simbal, biola, serta sebuah organ. Laras gamelan yang digunakan sudah disesuaikan dengan nada diatonis dengan pilihan nada bernuansa Timur Tengah. Untuk boneka wayang yang digunakan membawakan lakon, sama dengan pada pertunjukan WGGT di ISI Surakarta, namun sering kali tanpa simpingan, disesuaikan dengan situasi dan tempat pementasan berlangsung. Ketika saya berkesempatan mengikuti pementasan di daerah Jatinegara, Tegal, tata panggung tidak menggunakan simpingan wayang. Namun pada pementasan salah satu daerah di Brebes, Ki Enthus Susmono menggunakan baik simpingan maupun wayang sabet, kesemuanya adalah wayang golek Purwa Sunda. Begitu juga dengan iringan yang digunakan, terasa dominan menggunakan nuansa Sunda. Bahkan adegan pembuka dan jebol kayon, menggunakan iringan wayang golek Sunda seperti gending Kawitan lengkap dengan tarian boneka Maktal.

Eklektisme akan terlihat kentara dan mencolok ketika mengamati Ki Enthus Susmono mempertunjukan wayang kulit. Seperti pada pertunjukan di Taman Budaya Surakarta dengan Lakon Subali Léna atau Lakon Cupu Manik AsVagina di 2011 yang lalu. Wayang yang digunakan terdiri dari wayang purwa klasik dengan modifikasi teknik pewarnaan transparan, pepohonan, kayon Bali modifikasi yang ukurannya diperbesar dan isian ornamen yang diubah, kayon-kayon ciptaan Ki Enthus Susmono, serta tokoh Sabar Subur yang merupakan modifikasi punakawan Bali Merdah dan Tualen. Kelir yang digunakan adalah modifikasi yang dipopulerkan Ki Enthus Susmono, berbentuk setengah lingkaran dengan berhias gambar pulaupulau kecil di beberapa bagian atas kelir. Simpingan wayang yang digunakan adalah simpingan wayang purwa Ramayana (di bagian kanan seluruhnya wayang kera, mulai dari: Anoman Triwikrama, Sugriwa berukuran besar, Subali, Anoman, Anggada, dsb.; di bagian kiri seluruhnya bangsa raksasa) sepanjang sekitar 12 meter.

Iringan gamelan dan orkestrasi musik yang digunakan oleh Ki Enthus Susmono dalam setiap pementasannya juga sangat kentara dengan eklek tisme. Ia seringkali menggunakan bentuk-bentuk srepeg garap baru dengan laras pélog, namun kemudian mengkombinasikannya dengan srepeg
Sragènan dan srepeg Surakarta. Yang unik adalah, ketika menggunakan iringan srepeg nem gagrag Surakarta, Ki Enthus Susmono menggunakan beberapa bagian yang seperti sengaja dibedakan dengan yang lazim digunakan para dalang Surakarta. Selain menggunakan bentuk srepeg dengan berbagai varian dan dari berbagai sub gagrag kedaerahan di Jawa seperti Cék-dongan, Surakarta, Banyumasan, Sragènan, juga seringkali digunakan iringan Sunda. Namun yang kemudian justru menjadi penanda iringan Ki Enthus Susmono adalah bentuk-bentuk garap baru yang kadang menangkap nuansa kontemporer. Pada pertunjukan lakon Subali Léna di Taman Budaya Surakarta 2011, digunakan bentuk-bentuk baru yang dikombinasikan dengan penggunaan nuansa dan garap Bali. Salah satu iringan khas yang banyak digunakan oleh dalang-dalang di Indonesia adalah talu Burdah yang menangkap nuansa Jawa dan Islam, yang beberapa penggalan awal bagiannya sebagai berikut:

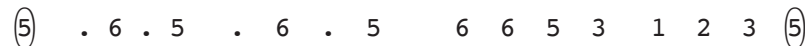
Balungan:

$\begin{array}{llllllllllllllll}1 & 3 & 21 & 2 & 1 & 3 & 21 & 6 & 1 & 3 & 21 & 2 & 3 & 1 & 6 & 5\end{array}$

Vokal:

$\begin{array}{llllllllllllllll}1 & 32 & 1 & 2 & 1 & 32 & 1 & 6 & 1 & 32 & 1 & 2 & 3 & 5 & 6 & 5\end{array}$

Ya Allah bi ha Ya Allah bi ha Ya Allah bi hus- nil kha- ti- mah

$\begin{array}{llllllllllllllll}1 & 32 & 1 & 2 & 1 & 32 & 1 & 6 & 1 & 32 & 1 & 2 & 3 & 1 & 6 & 5\end{array}$

Ya Allah bi ha Ya Allah bi ha Ya Allah bi hus- nil kha- ti- mah Seseg . . . $\quad 316$ (5)

Dados srepeg:

$\begin{array}{llllllll}45 & 5 & 4 & 5 & .56 & 5\end{array}$

Mau - la yaa shal - li was- sal- lim

- . $\overline{34} 5 \quad \cdot \sqrt{34} \overline{32} 1$

$\mathrm{Da}$ i- $\operatorname{man}$ a- ba da

$\begin{array}{lllllllll}\text { - } & 2 & 1 & 2 & \text {. } & 3 & 4 & 5\end{array}$

- A la- haa bii bi - ka

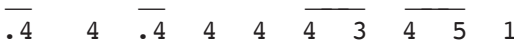

khai- ril khal- qi qul- li hil- $\mathrm{mi}$ [dan seterusnya..]

(Sumber: Nyi Eny Lestari, 2019)

Cerita lain, yaitu ketika $\mathrm{Ki}$ Enthus Susmono mendalang dalam rangka Harlah Partai Kebangkitan Bangsa ke-15 tahun 2013 dengan Lakon Pandhawa Bangkit. Pada adegan jebol kayon, ia menggunakan satu buah kayon mesjid, dua kayon kreasinya yang lain, kemudian bersolah membuat komposisi gerak kayon dengan proyeksi bayangan terlihat apik, didukung oleh tata lampu yang memadai. Adegan selanjutnya adalah tarian raksasa, 
lazim disebut dengan kiprah buta, menggunakan iringan dengan pola balungan Jawa, bernuansa Jawa Timuran, namun kendang yang mengiringi gerak tari kiprah buta adalah kendang Sunda yang dimainkan dengan pola Jawa Timuran.

Lakon Pandhawa Bangkit mengisahkan pengungsian Dewi Kunthi dan kelima putra Pandawa, setelah peristiwa pembakaran Balé Sigala-Gala oleh Kurawa. Pandawa berhasil menyelamatkan diri kemudian mengungsi di sebuah kerajaan bernama Ekacakra. Ketika mengungsi dan meminta sedekah makanan di rumah Demang Manahilan, mereka mendengar keributan dan kesedihan pemilik rumah, karena salah seorang anggota keluarga mereka saat itu harus menyerahkan diri sebagai korban, menjadi makanan penguasa Ekacakra. Prabu Baka, penguasa Ekacakra diceritakan sebagai pemakan manusia. Adegan yang menarik adalah ketika Semar dan ketiga anaknya sedang menasehati para Pandawa. Di situ nampak sekali peran Gareng, punakawan yang lazimnya diceritakan sebagai objek teraniaya akibat lelucon Petruk dan Bagong, justru menjadi seorang yang bijak, pandai, kritis, namun sekaligus nyebahi. Bahkan Semar, sebagai dewa Ismaya pun tak diberikan kesempatan berbicara oleh Gareng. Bentuk parodi dan ironi banyak mewarnai pertunjukan Ki Enthus Susmono malam itu melalui dialog-dialog lucu. Seperti dialog Prabu Baka dan Patih, yang selalu dipatahkan seorang Bilung, abdi yang oleh $\mathrm{Ki}$ Enthus digambarkan tidak mengenakan pakaian, punggung membungkuk, namun berani berbicara ceplas-ceplos.

BK :"Wis pirang désa hemm, korban sing takpangan dagingé sing takkokop getihé, sing tak remuk-remuk balungé, Patih?"

('Sudah berapa desa, korban yang kumakan dagingnya, kuminum darahnya, dan kuremuk-remuk tulangnya, Patih?')

PTH: "Sampun wonten tigang èwu kalih atus dhusun."

('Sudah ada tiga ribu dua ratus dusun.')

BK : "Negara Ekacakra pirang désa?"

('Negara Ekacakra punya berapa desa?')

PTH: "Wonten tigang yuta désa." ('Ada tiga juta desa.')

BK : "Woh hahahaha.. nganti pitung turunanku aku bisa mangan dagingé menungsa."

('Hahaha, aku bisa makan daging manusia hingga tujuh turunan.')

BL : "Permisi.. (tiba-tiba berjalan melewati raja dan patih)"

BK :"Lho, kowé sapa?"

('Lho, kamu siapa?')

BL :"Kula Bilung. Niki kula ajeng takèn kalih sampéyan bisané sampéyan dadi ratu, senengané mangan dagingé rakyaté keprimèn dhongé? Padahal angger nggoné agamané enyong tah ngomongé kaya kiyé: qullu kum ro 'im mas'ulu arro'yati. Setiap pemimpin pan ditakokaken tanggung jawabé. Lha tanggung jawaban kepada negara, kuwé latian bèn tanggung jawabé sampéyan modar...ning akhérat."

('Saya Bilung. Ini saya mau nanya sama sampeyan nih, gimana ceritanya sampeyan bisa jadi raja tapi seneng makan dagingnya rakyat sendiri? Padahal di agama saya, bilang gini: setiap pemimpin bakalan ditanyai pertanggungjawaban. Nah pertanggungjawaban negara itu buat latihan ntar tanggung jawab kalo sampeyan modar di akherat.')

BK :"Aku ora arep mati."

('Aku tidak bakalan mati.')

BL : "Alah ya sétan arané. Dituturi nemennemen koh."

('Wah, berarti setan dong namanya. Dinasehatin baik-baik kok.')

PTH: "Kowé aja mèlu-mèlu.."

('Kamu nggak usah ikut campur.')

BL : "(badan membalik menghadap patih) Lah sampéyan maning dadi patih dikongkoni gelem baé! Angger sing arané raja toli senengané mangan getihé rakyat sih kon pemimpin apa? Pemimpin kucing apa? Ki nyong mumpung dadi Mbilung."

('Nah sampeyan juga nih, jadi patih diperintah mau aja! Kalo raja makan daging rakyatnya sendiri, itu namanya pemimpin apaan? Emang pemimpin kucing? Ini saya mumpung jadi Bilung nih!

PTH: "Kowé ora wedi karo ratu gustimu?" ('Apakamu tidak takut pada pimpinanmu?')

BL : "Diwedèni apané wong padha déné wayang, kok répot. Kiyé ya wayang [tangan belakang diarahkan pada Prabu Baka], nyong ya wayang, mung bédané kiyé gedhé nyong 
cilik. Nyong tah bangsané kaya Cak Imin pendek cilik, kaya kuwé arané pendekar. "

('Apanya yang perlu ditakutin, wong samasama wayangnya. Ini wayang, dia juga wayang, cuma bedanya dia besar ini kecil. Saya mah sebangsa kaya Cak Imin pendek kecil, tapi pendekar.')

Dilanjutkan dengan dialog:

BK : "Yèn nganti Demang ora bisa mujudaké korban sing takpangan, Wijrapa sakanak bojoné kang minangka dadi korban."

('Kalau sampai Demang tidak bisa menyediakan korban, maka Wijrapa dan keluarganya yang akan jadi korban.')

BL : "Mudah-mudahan dhalangé ngudhunaken uwong sing bisa modaraken wong kiyé (sambil berjalan menunjuk Prabu Baka)." ('Semoga dalangnya ngeluarin orang yang bisa membuat mati orang ini.')

PTH: "Upamané kowé, gustimu Prabu Baka mati, kowé arep mèlu sapa?"

('Seandainya kamu, rajamu Prabu Baka mati, kamu akan ikut siapa?')

BL : "Alah, mengko mesthi isih akèh wong jahat. Mulané kiyé nyong ngomong angger ana ulama toli ora bisa ngandhani pejabat sing angkara murka, malah ulamané ndhukung marang pejabat sing korupsi, ésih mendhing Bilung. Angger Bilung bisa ngélingna wong sing ora apik. Angger ulama toli membèk-ap pejabat sing ora apik, iku arané ulama u'su, goblok!"

('Alah, ntar pasti masih banyak orang jahat. Makanya nih saya ngomong, kalo ada ulama tapi nggak bisa ngasih tau pejabat yang ngumbar angkara murka, malah ulamanya ngedukung pejabat yang korup. Masih mending Bilung. Kalo Bilung bisa ngingetin orang yang nggak baik. Kalo ada ulama tapI nge-bek-ap pejabat yang nggak baik, itu namanya ulama u’su, goblok!')

...........

Tiba-tiba dalang menyabetkan Bilung pada dua raksasa sambil bicara:

"Wis mana pan mèrèd, mèrèd, pan modar, modar wis! Yaa! Setrèss temen, wedang baé ra metu-metu acan koh! Adooh.."

[Menyanyi sambil bersolah, kepala dalang berlenggak-lenggok]
('Udahlah sana kalo mau pada mati, mati aja ya?! Stress nih. Dari tadi nggak keluar air-air acan sih! Aduuh..')

.........

"Haduh ya Allah.. Sing nonton aja padha kakèhan cocot wis meneng baé, modhalé modhal kari mangkat kok ribut.. Yalaahh... Wong angger arep dadi bathang rainé kéné ketara nemen kiyé [sambil mencolek bagian wajah sang raja]. Huuuuh, Ya Allah... [mencolek-colek wajah patih].”

('Aduh Ya Allah, yang nonton nggak usah pada ribut banyak omong ya, diem aja. Cuma modal berangkat doang aja pake pada ribut. Yalaah, orang kalo udah mau jadi mayat, mukanya pada keliatan tuh.')

Adegan ketika Pandawa bersama Punakawan beristirahat sebelum memasuki Dusun Manahilan, Kyai Semar memberikan petuah agar senantiasa bersabar menghadapi cobaan. Tiba-tiba Petruk dan Gareng muncul lalu ikut dalam obrolan.

Tentang Gus Dur..

GR : "Ki Gus Dur lagi nonton kiyé bengi iki mau sms karo nyong ndarani apa sih? Ndarani apa? Eeh ora ngandel taktelpon. Assalamu'alaikum, Gus.."

('Malam ini Gus Dur lagi nonton kita nih. Kalo nggak percaya, ditelpon.')

GD : "A'laikumsalam. [mirip suara Gus Dur]"

GR : "Saweg mirsani, Gus?"

('Lagi nonton ya Gus?')

GD : "Yaa saya melihat wayang. Itu keponakan saya Si Imin ada di situ. Ya, saya mengucapkan terima kasih pada Tarzan, Gogon, dan Marwoto juga. Sss.. begitu saja kok repot."

GR : [berbalik badan] "Gus Dur kuwé nganti sepréné durung ditakoni malaikat yakin!"

('Gus Dur kamu sampai sekarang belum ditanya malaikat yakin!')

PTR : "Kowè ki aja ngawur lho Rèng!"

(Kamu tuh jangan ngawur lho, Reng.')

GR : "Ee dikandhani kok ra nggugu sib?"

(Idih, nggak percaya amat sih.')

PTR : "Dhasarmu?"

('Apa dasarnya?')

GR : "Ya jaré wong NU uniné angger bar ngubur, toli sing takziah mlangkah pitung langkah..?” 
('Kan kata orang NU kalo habis ngubur, yang takziah balik tujuh langkah..')

PTR : "Malaikat teka.."

('Malaikat datang.')

GR : "Nah.. saiki nyong taktakon, kuburané Gus Dur kuwé kapan sepiné? Kapan lé sepiné? Apa maning pitung langkah, nembé telung langkah ana uwong maning.. nembé rong langkah ana uwong maning.. malaikaté pan marani, ana uwong, lunga maning! [Gareng memperagakan malaikat pergi menghindar] Malaikaté set. pan marani, ana uwong lunga maning! Malaikat nganti eneg kuwé ngurusi Gus Dur. Tenan wis.. Angger ditakoni malaikat, Man rabbuka..? Gus Dur mesthi jawabé, udah tau, nanya." ('Nah, sekarang aku tanya deh, makamnya Gus Dur kapan sepinya coba? Baru tiga langkah ada yang mundur, datang lagi yang baru, malaikat datang langsung pergi lagi. Sampe-sampe malaikat udah eneg ngurusin Gus Dur. Kalo ditanya, siapa Tuhanmu? Jawaban Gus Dur: udah tau nanya.')

BG : "Wah jan menarik iki."

('Wah menarik banget ini.')

GR : "Yaa menarik. Wong nyong bè angger kayong pentas Jawa Timur mesthi mampir maring Gus Dur."

('Ya pasti menarik. Orang kalau aku habis pentas di Jawa Timur saja pasti mampir ke makam Gus Dur.')

PTR : "Lah.. Lebaran, hayo..? Kuburané sepi." ('Nah, kalo lebaran pasti sepi.')

SMR: "Oh iya kuwi, lebaran sepi."

GR : "Eh wong tuwa meneng wae aja mèlumèlu..sst! Wong tuwa ana wong kritis sithik, tersinggung. Brrrr [mencolek bibir Semar]. Lebaran bener kuwé. Malaikat ya ngarep-arep, iyaaah mengko lebaran.. jaréné malaikat. Bareng pas bada kan kuburané sepi? Set. Malaikat teka. Malang kerik o malaikaté, gemes si karo Gus Dur. Man rabbuka.."

('Eh, orang tua diem aja sih nggak usah ikutan ngomong. Orang tua kalo ada anak muda kritis dikit suka tersinggung. Iya, lebaran bener. Malaikat juga udah ngarepin sepi pas lebaran. Dia datang sambil gemes banget sama Gus Dur. Man rabbuka?')

PTR : "Trus Gus Dur jawabe?"

('Trus, Gus Dur jawab apa?')

GR : "Sampeyan ini malaikat model apa? Malaikat kok telat? [suara Gus Dur] Lho, telatnya di mana? [Malaikat] Orang yang ditanya man rabbuka kan orang yang baru meninggal, lha saya sudah meninggal lama kok baru ditanya man rabbuka? Morinya saja sudah bosok masa malaikat kok telat? [suara Gus Dur] Mlayu maning kok malaikaté ora wani [Gareng memperagakan larinya malaikat]. Akhiré malaikat dikumpulna nganakaken rapat darurat."

PTR : "Nang ndi kuwi?"

GR : "Kantor sekretariat permalaikatan. Akhiré Gus Dur kuwé dingèhi sertifikat Husnul Khotimah.

BG : "Terus akhirè Gus Dur piyè?"

('Terus Gus Dur akhirnya gimana?')

GR :"Dingéhi sertifikat Husnul Khotimah."

('Dikasih sertifikat Husnul Khatimah.')

BG : "Rèng, aku péngin angger mati ora ditakoni malaikat piyé carané Rèng?"

('Reng, aku juga pengin kalo mati nggak ditanyai malaikat gimana caranya Reng?')

GR : "Gampang! Kon mengko angger balik, tulung amanat karo bojoné kon ya kena, karo tanggané kon ya kena."

('Gampang. Ntar kamu wasiat sama keluarga ato tetangga juga boleh.')

BG : "Amanat priyé Rèng?"

('Wasiat gimana Reng?')

GR : "Angger kon mati bésuk aja dibuntel nganggo mori. Dibuntel nganggo godhong! Dadi angger malaikat takon, man rabbuka.. nyong dudu uwong, nyong lonthong! [sambil bicara, badan Gareng ditekuk-tekuk ke bawah] kaya kuwé, ya slamet.."

('Besok kalo kamu mati, minta jangan dibungkus kain mori, tapi daun. Jadi kalo malaikat nanya, Man rabbuka? Jawabnya, saya bukan orang, tapi saya lontong, gitu, pasti slamet.')

Dialog-dialog pada adegan di atas memperlihatkan akrabnya Ki Enthus Susmono dengan realitas dan keseharian. Dialog-dialog 
antara Prabu Baka, Patih, dan Bilung adalah parodi kehidupan yang ironinya dapat dirasakan di banyak tempat. Ia tidak hanya sedang menjewer telinga salah satu pihak yang saat itu sedang duduk dalam gelimang kesenangan di atas penderitaan dan kesengsaraan pihak lain. Pemimpin yang gemar makan daging, minum darah, dan menghisap tulang belulang rakyatnya sendiri, adalah gambaran ketimpangan sosial di lini-lini bawah kehidupan masyarakat, yang masih terasa di berbagai tempat. Namun secara khusus, kata-kata seperti "pejabat" dan "ulama" sepertinya memang ditujukan sebagai kritik tajam kepada beberapa tokoh pejabat berkuasa dan pemuka agama yang dalam konteks politik saat itu terlibat beberapa kasus dan mencuat ke permukaan. Di antaranya adalah kasus impor daging sapi oleh pejabat, aktivis partai, sekaligus berasal dari kalangan pemuka agama.

Adegan dan dialog yang menunjukkan interaksi para denawa atau bangsa raksasa (buta), terkadang memperlihatkan kenaifan, kebodohan, bahkan kelucuan. Adegan buta-buta ini kentara terlihat dalam pertunjukan wayang golek, seperti dalam pertunjukan wayang golek Sunda. Sependapat dengan Sarah Anaïs Andrieu (2017) dalam, Raga Kayu Jiwa Manusia Wayang Golek Sunda, bangsa raksasa yang dulu adalah sosok menyeramkan, jorok, kejam, agaknya kini telah mengalami penghalusan peran. Mereka menjadi figur-figur lucu, bodoh, menyebalkan, dan konyol (Andrieu, 2017: 326). Seperti pada adegan Prabu Baka berdialog dengan patih dan Bilung, mereka para raksasa terlihat bodoh di depan Bilung hingga tak berdaya ditelanjangi kecacatan akhlak mereka, yang menurut Bilung terlalu nista. Prabu Baka si pemakan manusia pun, tak kuasa membalas, mengelak, tidak murka kemudian memangsa Bilung. Ia seperti berkaca melihat sosoknya sendiri yang ternyata hanya gagah dan menyeramkan dalam tampilan, tapi sebenarnya wagu, naif, jauh dari kategori intelektual. Prabu Baka dan Patih di depan Bilung tak ubahnya hanya premanpreman kampung atau pemalak pasar yang hanya mengandalkan modal asal seram dan berani nekat.

Bilung, dalam cerita adalah sosok punakawan yang dilahirkan dari bayangan Togog, yang adalah Sang Hyang Antaga kakak tertua Sang Hyang Ismaya dan Sang Hyang Manikmaya. Mereka terlibat sengketa kekuasaan, hingga mendapatkan kutukan. Antaga menjadi Togog ditugaskan turun ke bumi menjadi pendamping dan penasehat pemuja angkara, sementara Ismaya terkutuk sebagai Semar yang diutus turun ke bumi menjadi penasehat para satria. Bilung yang lahir dari bayangan Togog, lazim diceritakan dalang sebagai punakawan dengan pembawaan watak yang berani, ceplas-ceplos, lucu, dan kritis. Dalam adegan di atas, ia merepresentasikan suara arus bawah, kaum gurem, yang terdesak sehingga berani lantang berbicara ketika bertemu dengan momentum. Namun sebagai kaum gurem, meskipun ia menyuarakan realitas kepahit-getiran kaum bawah dan terpinggir, meskipun realitas mereka sering kali tepat didengar, mencoreng bahkan menelanjangi kaum elit bermasalah, suara mereka hanya dilihat dan didengar. Hanya cukup sampai di situ, ia tetaplah gurem. Suaranya tidak pernah ditindaklanjuti, dihiraukan, senyap, kemudian lenyap.

Kritik atas konflik internal dan perpecahan yang sempat terjadi di tubuh Partai Kebangkitan Bangsa waktu itu, juga menjadi bahan-bahan garapan satir Ki Dalang. Ia juga pandai membuai. Parodi kematian melalui kisah Gus Dur dan malaikat, serta wasiat untuk Bagong agar berwasiat mati dibungkus daun, di satu sisi memperlihatkan parodi betapa otoritas Tuhan melalui malaikat dapat dengan sangat tidak berdaya dipermainkan oleh manusia bernama Gus Dur, guru bangsa yang ketika hidup menjadi Kyai NU kontroversial, setelah meninggal pun masih membuat geger otoritas kekuasaan Tuhan. Ki Enthus Susmono seperti ingin mengatakan bahwa Gus Dur ketika hidup sempat terzhalimi, namun sebagai guru bangsa ia berhasil menundukkan otoritas Tuhan. Namun ironi di sisi lain yang ingin dikatakan, bahwa betapa budaya negosiasi, tawar menawar, dan praktik penyalahgunaan wewenang otoritas hukum di negeri ini sangat parah.

Dari rekaman-rekaman pertunjukan $\mathrm{Ki}$ Enthus Susmono yang saya kumpulkan dan amati, baik wayang kulit, wayang santri, maupun wayang golek gagrag Tegalan (WGGT ISI Surakarta), dari tahun rekaman 1997 hingga 2018, memperlihatkan konsistensi gaya personalnya yang selalu ngédan. Ia konsisten menggunakan bentuk-bentuk dan strategi representasi seni postmodern yang eklektis, parodi, dan ironi. Bentuk-bentuk itu dapat 
diamati dari penggunaan dan pemilihan iringan, boneka wayang, kostum, instrumen, kemudian penggarapan dialog-dialog satiris, ironi, melalui humor maupun umpatan-umpatan. Ketiga bentuk representasi seni postmodern tersebut dibalut dalam kemasan keseluruhan caking pakeliran yang mencerminkan kebaruan gagrag. Selanjutnya akan dibahas analisis hubungan antara gagrag, kebaruan dan tindakan performatif, sesuai dengan pembacaan performativitas oleh Shoshana Felman (2003), dalam The Scandal of The Speaking Body.

\section{Wayang Gagrak Tegal dan Skandal Performatif Don Juan}

Ketika orasi kebudayaan sebelum Ki Enthus Susmono naik ke atas pentas membawakan Wayang Golek Gagrag Tegalan (WGGT) lakon Kembang Wijaya Kusuma di Pendapa Ageng Joyokusumo ISI Surakarta 8 November 2016 lalu, ia mengatakan (klaim) bahwa pertunjukan yang ia bawakan "asli" Tegal. Pada kesempatan itu juga ia menyerahkan dua buah buku yang ditulisnya, Wayang Gagrak Tegal dan Pakeliran Wayang Gagrak Tegal Jati Kusuma (2016), sekaligus sempat melontarkan ajakan, "tantangan", bahwa wayang gagrag Tegalan akan siap bersaing dengan gagrag-gagrag lain di Nusantara. Jika dilihat dalam cara pembacaan teori tindak tutur, maka apa yang ia katakan mengenai (klaim) "keaslian" gagrag Tegalan dan ajakan atau "tantangan" bersaing dengan gagrag lain, adalah kategori tindakan performatif.

Setelah mengamati temuan atas fenomena dan performativitas Ki Enthus Susmono di panggung maupun di luar panggung dengan cara pandang as performance dalam payung performance studies, rupa-rupanya dijumpai kemiripan cara dan strategi yang digunakan oleh J.L Austin (1962) dalam, How to Do Things With Words; studi Shoshana Felman (2003) dalam, The Scandal of Speaking Body membaca mitos Don Juan, serta Ki Enthus Susmono (2016) dalam Wayang Gagrak Tegal dan Pakeliran Wayang Gagrak Tegal Jati Kusuma. Dari ketiganya, dapat ditarik poin yang sama, yakni mengenai tindakan janji melalui ajakan, bujukan, godaan, atau rayuan. Klaim "asli" gagrag Tegalan, "tantangan" dan ajakan bersaing, dapat dibaca sebagai tindakan "janji” dalam teori tindak tutur Austinian, maupun janji pernikahan yang dibuat Don Juan kepada para perempuan korban rayuannya. Dengan kata lain, Ki Enthus Susmono saat itu sedang menjanjikan kepada khalayak, khususnya para dalang, akan mengusung gagrag Tegalan agar sejajar dengan dua gagrag besar keraton di Jawa. Dalam konteks yang lebih khusus malam itu, menyaingi gagrag Surakarta. Berdasarkan fenomena tersebut, maka pada bagian ini, proses analisis akan mengacu pada studi Felman membaca Austin melalui pembacaan teater dan mitos Don Juan.

Tindakan Don Juan menjanjikan pernikahan berulang-ulang pada perempuan-perempuan korban rayuannya namun gagal untuk menepatinya, adalah skandal rayuan. Setiap kali berjanji, ia tidak bisa menepatinya kemudian membuat janji baru pada korban yang baru lagi. Tindakan Don Juan yang berulang kali ini kemudian menjadi mitos, laki-laki penggoda dengan rayuan maut dan janji palsu. Gagasan pengulangan janji sebagai tindakan performatif inilah yang digunakan Felman mengkritisi keambiguan Austin dalam teori tindak tutur, How to Do Things With Words, dengan pisau analisis filosofi, linguistik, dan psikoanalisa Lacanian. Hasilnya, gagasan pengulangan dan status referensi diri tindak tutur sebagai pusat performativitas. (Ana Vulic, From a Misfire to an Open Future: Repetition, Performativity and the Promise of the Metaphor, 2012: 1)

Seperti telah dibahas di muka, Ki Enthus Susmono bermain-main dengan idiom tradisi membuat penanda baru melalui representasi strategi seni postmodern, eklektis yang terdiri dari parodi-parodi, maupun bentuk-bentuk ironi. Bentuk parodi maupun ironi di antaranya melalui permainan bahasa dalam guyonan, pisuhan, maupun kritik, bahkan gerakan tubuh yang edan-menggila seolah kerasukan, seperti: berdiri dan berkelahi memukuli wayangnya sendiri, membuat penonton tercengang tak terpikirkan karena di luar konvensi umum: konstruksi yang disebut sebagai etika bagi orang Jawa. Ki Enthus Susmono pandai memainkan dan bermain-main dengan idiom wayang. Namun demikian, ia tidak berarti mempermainkan wayang. Ki Enthus Susmono tetaplah seorang dalang yang teguh pada penceritaan dan alam pikir jagat wayang. Adegan serius, mencekam, sedih, tetap ia ceritakan dengan penghayatan, sebagaimana para dalang 
menyebutnya dalam konsep dhalang manuksméng wayang. Ia menubuh, menghidupi boneka-boneka wayang, tubuh keduanya melalui nafas dan jiwanya sebagai dalang.

Ki Enthus Susmono setia pada penceritaan, karena fiksi dalam jagat wayang adalah kepuasan dan kenikmatan bagi dalang. Ketika dalang menghidupi wayang sebagai tubuh keduanya, ia memproduksi wacana melalui tindak tutur (caking pakeliran) dalam sebuah penanda yakni gagrag. Jika fiksi wayang adalah kenikmatan, maka gagrag yang memuat caking pakeliran adalah hasrat (desire) bagi dalang. Gagrag bertindak sebagai lembaga caking pakeliran, keseluruhan tindak tutur dalang, yang memuat semua aspek gejala kebahasaan. Maka dengan kata lain verbalisasi, caking pakeliran, dan gagrag adalah hasrat seorang dalang. Dalang akan selalu menggunakan tindakan tubuh sebagai bahasa untuk mencapai kenikmatan fiksi, melalui produksi gerak visual wayang, tubuh dalang, dan tuturan sebagai aspek verbal, yang adalah tindak tutur ilokusi sehingga mendapatkan reaksi penonton. Dalang seperti Ki Enthus Susmono pandai memainkan tuturan menggoda, mengajak, mengancam, untuk menghasilkan ilusi-ilusi agar penonton terbuai.

Melalui ujaran rayuan yang menggoda dan membuai lewat bahasa itulah, Ki Enthus Susmono sukses menjadi dalang kontroversial dan menjadi mitos dalam dunia pedalangan sebagai dalang edan penabrak "pakem”. Kesuksesan Ki Enthus Susmono sama dengan kesuksesan Don Juan menjadi mitos atas pengulangan tindakannya menggunakan rayuan untuk berjanji yang tidak pernah ditepati. Kemudian bagaimana Ki Enthus Susmono bisa diposisikan setara dengan mitos Don Juan? Seperti telah disinggung di awal bagian ini, kontroversi terjadi setelah Ki Enthus Susmono mengatakan (klaim) gagrag Tegalan dengan pernyataan mengenai otentisitas identitas Tegal menjadi ambigu, karena pada praktiknya, apa yang ditulis dalam buku dan pertunjukan yang dibawakan berbeda. Dalam pertunjukan, seperti dalam panggung-panggung lain sebelumnya, ia membawakan ciri personal sebagai gagrag Enthus: eklektis. Maka wacana wayang gagrag Tegalan yang diusung bermuatan guyon-humor-tidak serius. Kegagalan "Wayang Gagrak Tegal' Ki Enthus Susmono, sama seperti kegagalan Don Juan menepati janji pada perempuan yang dijanjikannya menikah. Ki Enthus Susmono terus mengulangi janjinya yang dieksplisitkan melalui ajakan-tantangannya berkompetisi melalui “Wayang Gagrak Tegal" tetapi gagal untuk ditepati (skandal).

Pernyataan Ki Enthus Susmono (WGGT $L K W K)$ :

SLT : "Sindénan di akhir iringan, namanya sèlèhan. Ini juga ciri khas wayangan gagrag Tegal. Siap bersaing dengan gagrag-gagrag lain di tanah Jawa dan di Indonesia. "Wayang Gagrak Tegal" sudah ada bukunya, sudah dites senat di hadapan dewan senat Universitas Negeri Semarang. Siap untuk dites di Institut Seni Indonesia Jurusan Pedalangan."

Pernyataan Ki Enthus Susmono di atas, dapat dibaca sebagai kalimat ajakan, tantangan, sekaligus tindakan menjanjikan, WGT bersaing dengan gagrag lain di Nusantara. Jika merujuk pada $W G T$ (Wayang Gagrak Tegal) dan PWGT-JK (Pakeliran Wayang Gagrak Tegal Jati Kusuma) yang dipublikasikan Ki Enthus Susmono pada 2016, yang dimaksud dengan ajakan, janji, dan tantangan tersebut adalah gagrag Tegal yang diklaim asli sebagai bentuk penyajian tradisi. Namun ternyata pernyataan tersebut menjadi ambigu atau paradoks, karena pada kenyataannya pertunjukan WGGT LKWK yang disajikan berbeda dengan pola sajian seperti yang dijelaskan dalam kedua bukunya ( $W G T$ dan PWGT-JK). Pertunjukan WGGT LKWK bukanlah bentuk sajian tradisi, melainkan sajian dengan penghadiran bentuk-bentuk eklektis atau hibridis, sama halnya dalam sajian Ki Enthus Susmono dalam setiap penampilan di panggung-panggung pertunjukan ketika mendalang wayang kulit. Penghadiran eklektisme yang hibridis dalam setiap pertunjukan dan panggung Ki Enthus Susmono sebelum dan setelah publikasi $W G G T$ dan $W G T$ di ISI Surakarta maupun Yogyakarta, dapat dibaca sebagai tindakan pengulangan kegagalan Ki Enthus Susmono menjaga janji, bersaing menggunakan sajian garap tradisi Tegal (WGT dan PWGT-JK).

Jika dikaitkan dengan kemiripan yang ditemukan dalam pembacaan tindakan janji atau menjanjikan melalui rayuan dalam Felman (2003) yang membaca teater Don Juan karya Molieré, Felman mengatakan: 
"one might say that the Don Juan myth of the mouth is the precise place of mediation between language and the body. Don Juan's mouth is not simply an organ of pleasure and appropriation, it is also the speech organ par excellence, even the organ of seduction" (Felman, 2003: 37)

('Bisa dikatakan bahwa mitos mulut Don Juan adalah tempat mediasi yang tepat antara bahasa dan tubuh. Mulut Don Juan bukan hanya organ kesenangan dan aprosiasi, tetapi juga organ wicara yang luar biasa, bahkan sebagai organ rayuan').

Felman menunjukkan bahwa janji itu berfungsi sebagai rayuan bagi Don Juan yang dilanggar berkali-kali. Tindakan Don Juan yang melanggar janji itu tidak dapat mewakili niat dengan kepastian, maka tidak dapat diprediksikan bagaimana tindakan selanjutnya di masa depan (setelah mengucap janji). Menjanjikan pernikahan dengan rayuan bagi Don Juan adalah tindakan yang hanya merujuk pada tindakannya sendiri dan upaya untuk mengubah sesuatu dalam situasi tindak tutur di mana itu terjadi (Felman, 2003: 14). Jadi dapat dikatakan bahwa suatu tindakan tertentu memang dilakukan dengan mulut sebagai organ tubuh, tetapi tidak berarti bisa membuktikan isi atau kekuatan dari sebuah ucapan.

Hubungan antara keduanya menjadi jelas hanya setelah kita memahami hubungan antara janji, rayuan, dan pernikahan. Felman, perkawinan menjadi contoh bagi tindak tutur. Janji adalah tindak tutur yang mewakili niat sepanjang waktu, dan pernikahan adalah tindak tutur yang mewakili disposisi tubuh seksual sesuai dengan konsistensi dan kesetiaan. Jika janji itu tidak hanya terkait dengan pernikahan tetapi sangat penting untuk sumpah pernikahan, maka tindak tutur dalam contoh itu tidak hanya mewakili tubuh, tetapi juga merupakan tindakan tubuh karena ia mendedikasikan dirinya melalui waktu kepada seseorang yang kepadanya dan dengan siapa ia bersumpah. Menjanjikan sesuatu tidak mencerminkan niat, melainkan untuk memaksa tubuh agar bertingkah laku sendiri, secara konstan, terhadap yang lain.

Jika Don Juan menjadi mitos seorang lakilaki "jago rayuan maut" yang berhasil membuai dan mengelabui perempuannya, maka Ki Enthus
Susmono menjadi mitos seorang dalang yang ahli membuai tindakan ngédan atau menggila, lewat ajakan verbal dan visual di pertunjukan wayang. Maka berdasarkan keterangan tersebut dapat dikatakan bahwa ajakan, tantangan bersaing, atau dibaca sebagai tindakan janji Ki Enthus Susmono dengan (klaim) "Wayang Gagrak Tegal" adalah tindak tutur yang sekaligus adalah tindakan tubuh yang tidak dapat dibaca sebagai niatan, melainkan strategi sementara untuk mewujudkan hasrat dalam bahasa.

Menyarikan Judith Butler dalam kata penutup tulisan Felman (2003: 119-121) Don Juan, melakukan janji tanpa pernah menempatkan tindakannya sebagai sebuah kemungkinan yang murni. Tubuh menandakan apa yang tidak disengaja, berbeda dengan niat dan kesadaran, karena tubuh menjadi kendaraan untuk tindak tutur. Bahasa rayuan adalah apa yang dilakukan tubuh, yakni tindakan tubuh saat ini, pada saat yang sama ia menandakan apa yang akan dilakukan tubuh. Maka dalam transferensi yang diterangkan Felman, pembicara tidak sepenuhnya atau mengendalikan apa yang diartikulasikan dalam ucapan. Felman (2003: 51) mengatakan:

"Referential knowledge of language is not knowledge about reality (about a separate and distinct entity), but knowledge that has to do with reality, that acts within reality, since it is itself at least in part what this reality is made of. The referent is no longer simply a preexisting substance, but an act, that is, a dynamic movement of modification of reality".

('Pengetahuan referensial bahasa bukanlah pengetahuan tentang realitas (tentang entitas yang terpisah dan berbeda), tetapi pengetahuan yang berkaitan dengan realitas, yang bertindak dalam realitas, karena ia sebagian dari realitas. Referen bukan lagi sekadar substansi yang sudah ada sebelumnya, tetapi suatu tindakan, yaitu gerakan dinamis dari modifikasi realitas').

Tindakan performatif, dipahami sebagai ilokusi, menunjukkan realitas, bahkan mengubahnya, sebagai hal yang biasa, berusaha untuk mengubah situasi, untuk memiliki efek tertentu. 
Ucapan adalah bagian dari bahasa yang melebihi pernyataan, tetapi, bahasa memiliki tujuan sendiri yang melebihi tujuan yang diwakili oleh pernyataan. Felman berspekulasi bahwa nonsemantic excess, yang disebut Austin sebagai "kekuatan," adalah karakter pulsional dari hasrat dalam bahasa, desakan tubuh karena ia memotivasi sekaligus menggagalkan cara bicara. Bahasa, memiliki maksud yang melebihi kekuatan sekadar ucapan dan niat si pengucap (Felman, 2003: 51). Dengan demikian strategi eklektis, parodi, dan ironi Ki Enthus Susmono ketika mendalang menunjukkan realitas tindakan tubuhnya, diproduksi berulang-kali menjadi kebiasaan (ciri khas-mitos), yang dilakukan untuk menghasilkan efek tertentu. Ketika wacana "keaslian Tegal" ditawarkan, ia tidak mewakili niat sebenarnya, karena hanya bagian dari salah satu strategi Ki Enthus Susmono ketika hasratnya mendesak dan memotivasi menggagalkan tawaran wacana "keaslian" gagrag Tegalan.

Kemudian mengapa gaya pertunjukan $\mathrm{Ki}$ Enthus Susmono yang menjadi mitos sebagai dhalang édan dengan kekhasan gaya personal eklektis, parodi, ironi, ketika mendalang dapat diterima dan digandrungi bahkan diadopsi banyak orang? Pertunjukan wayang postmodern yang tetap asyik dan dapat dinikmati oleh penggemar wayang serta khalayak ramai. Apa sesungguhnya yang terjadi dalam interaksi antara Ki Enthus Susmono dan penonton wayang era sekarang?

Pertanyaan-pertanyaan tersebut dapat terjawab dengan menggunakan perspektif Lacanian. Dalam studi kasus gagrag sebagai kritik seperti yang dilakukan oleh Ki Enthus Susmono, ia (Ki Enthus Susmono) dapat dibaca sebagai pihak yang merepresentasikan orang-orang terasing, merasa bosan, tidak cocok, yang direpresi oleh pakem gagrag pedalangan keraton, karena tidak sesuai dengan gairah atau hasratnya (desiring subject) untuk mencapai kenikmatan fiksi wayang. Hasrat bagi seorang dalang adalah mendalang dengan rangkaian teknis tata cara mendalang (caking pakeliran). Dengan kata lain, gagrag yang berisi serangkaian cara dan kreatifitas dalang mengekspresikan diri adalah hasrat. Sedangkan kenikmatan dalang adalah ketika mencapai kenikmatan fiksi wayang. Sehingga seringkali dalam istilah para dalang disebutkan kalimat: "dhalang kuwi suwarganè yén lagi mayang" (surganya dalang itu ketika sedang mendalang). Dalam hal ini gagrag keraton/ istanasentris tidak dapat memberikan kepuasan atau kenikmatan fiksi bagi Ki Enthus Susmono, yakni ekspresi kesenimanan sebagai dalang untuk mencapai ekstase dalam jagat wayang, karena ia terbelenggu dengan berbagai aturan dan ikatan kepura-puraan yang disebut pakem adilubung (seperti dalam kalimat: tontonan yang mengandung tatanan, dan tuntunan).

Gagrag dua keraton besar di Jawa SurakartaYogyakarta (keraton-rezim militer) adalah primary signifier melalui: bahasa; boneka wayang; iringan dan rasa musikal; dramaturgi dan pengadegan; pakem dan caking pakeliran; bertindak sebagai bahasa liyan (other) yang terus menerus dituliskan kepada para dalang sebagai standard ideal gagrag pedalangan, karena gagrag keraton melalui para pemegang otoritas memiliki kecenderungan untuk menghakimi, menatap, dan menstandardisasi. Fenomena gagrag dan performativitas Ki Enthus Susmono, memiliki kemiripan dengan yang dilakukan oleh Hardjasoebrata menggubah lagulagu gerejani cara Landa menjadi cara Jawa. Maka pembacaan fenomena Ki Enthus Susmono mengkritisi gagrag juga dilakukan merujuk pada pembacaan Sunardi (2012: 385-397), Lagune Cara Landa kok Tembunge basa Jawa: Perspektif Pascakolonial dalam Kajian Religi, Vodka dan Birahi Seorang "Nabi": Esai-esai Seni dan Estetika.

Hal ini tidak memberikan Ki Enthus Susmono ruang kenikmatan fiksi ketika begitu saja diikuti dengan kepatuhan. Ketika Ki Enthus Susmono menampilkan gayanya yang berbeda dengan konstruksi pakem gagrag dua keraton, ia distigmakan nakal, serta édan.

Para pemegang otoritas gagrag dalam dunia pedalangan melalui konstruksi "pakem adilubung" merepresentasikan kekuasan rezim, sekaligus mengeksploitasi pihak lain dengan hegemoni. Hegemoni yang ditancapkan, diikuti dengan praktik kekerasan budaya oleh penguasa Orde Baru telah mempengaruhi berbagai aspek kehidupan masyarakat mulai dari paradigma, pola kehidupan, relasi sosial, dan wacana sosial. Hal ini terjadi karena penguasa melakukan kontrol yang sangat ketat guna menghadirkan situasi "aman" bagi kehidupan masyarakat Indonesia. Jika menyarikan dan meminjam pengandaian yang dilakukan Shiraishi (2009) dalam Pahlawan- 
Pahlawan Belia, penguasa saat itu memperlakukan Indonesia sebagai gambaran sebuah keluarga, yang terdiri dari "bapak, ibu, dan anak-anak". Penguasa rezim berperan sebagai bapak, yang akan mengontrol dan mengawasi perilaku anak-anaknya. Kontrol tersebut dirasakan begitu ketat oleh setiap warga negara, yang jika diibaratkan seperti berada di dalam ruang interogasi. Di luar ruangan siapa saja dapat bergerak dengan bebas, tetapi di balik kaca atau tembok yang tak terlihat sosoknya, ada bapak yang akan mengawasi segala perilaku tadi.

Pertama kali, pengaruh gagrag keraton menjadi dominan melalui sekolah-sekolah pedalangan yang dibentuk. Kemudian pada konteks historis ketika Karesidenan Surakarta sangat terdampak pada peristiwa pembersihan 1965 banyak dalang dan seniman terlibat sebagai simpatisan partai komunis, maka militer sebagai representasi rezim penguasa mengawali pengambilalihan otoritas seniman dalang dengan membentuk lembaga Ganasidi 1969 (Groenendael, 1987: 216-237). Dalam perkembangannya Ganasidi menjadi Pepadi (Persatuan Pedalangan Indonesia) pada 1971 yang kemudian bersama Senawangi menjadi otoritas sebagai perwujudan lain pengawasan penguasa pada dalang mengeksploitasi idiom-idiom budaya keraton sebagai legitimasi kuasa. Karena Surakarta menjadi daerah terdampak parah pada peristiwa 1965, maka dapat dimungkinkan hal itu menjadi alasan awal mula otoritas penguasa memilih Surakarta sebagai kiblat standardisasi kebudayaan nasional, khususnya gagrag pedalangan, di samping gagrag Yogyakarta. Selain itu, institusi pendidikan yang dibuat, bertindak sebagai pengemban dan konservasi gagrag (ASKI menjadi STSI, sekarang ISI), dalam perjalanannya dapat dikatakan ikut tereksploitasi akibat hegemoni penguasa, menjadi mitra penyebarluasan pewartaan dan otoritas gagrag pedalangan.

Usaha Ki Enthus Susmono mengusung TegalPesisiran dengan klaim, ajakan, janji, Wayang Gagrak Tegal (2016) adalah upaya untuk mencari signifikansi di antara dua gagrag keraton. Gagrag Enthus Susmono yang mengusung Tegal-Pesisiran adalah efek pencarian identitas menjadi genre baru, kebaruan gagrag, yang tidak lagi murni Tegal atau Pesisiran. Ia dapat dibaca sebagai simtom subjek yang terbelah, yakni pihak yang dipaksakan menganut paham kebudayaan Surakarta-Yogyakarta atau gagrag keraton. Gagrag Enthus Susmono dibaca sebagai kebaruan karena kemudian menjadi titik pertemuan kultur-kultur baru: Jawa (Surakarta, Yogyakarta), Tegal, Pesisiran, Sunda, Islam, dan kontemporer, melalui strategi-strategi ngédan sebagai representasi seni postmodern: eklektis, parodi, dan ironi.

\section{Penutup}

Rupa-rupanya gagasan performativitas Shoshana Felman mengenai tindakan performatif berulang menemukan keterbatasan ketika digunakan dalam menganalisis fenomena $\mathrm{Ki}$ Enthus Susmono. Dengan mengkombinasikan antara strategi seni postmodern: eklektis, parodi, dan ironi, ternyata performativitas juga perlu didukung oleh interaktivitas yang intens dan menyeluruh. Sebagaimana pada contoh kasus Ki Enthus Susmono, kegagalan janji berulang dan strategi representasi seni postmodern didukung oleh totalitas interaksinya dengan berbagai hal, seperti boneka wayang, musik, penonton, gaya panggung, bahasa, sehingga berhasil membuai dan menggiring ilusi pada kesadaran kolektif memasuki kenikmatan fiksi wayang bersama-sama.

Ajakan dan tantangan Ki Enthus Susmono dengan klaim keaslian gagrag Tegalan melalui $W G G T$ dan dua buku karyanya, ternyata dapat dibaca sebagai tindakan menjanjikan sebagaimana Don Juan berjanji lewat rayuan maut pada perempuan korbannya. Dari pembacaan itu ditemukan, bahwa Ki Enthus Susmono sama seperti halnya Don Juan, berulang kali telah gagal menepati janji untuk menyajikan keaslian gagrag Tegalan, karena apa yang ia tulis dengan apa yang ia sajikan saling bertolak belakang. Kegagalan berulang tersebut menjadi sebuah keniscayaan realitas menjadi penanda kebaruan gagrag Tegalan.

Kebaruan yang dimaksud dalam gagrag Tegalan, tidak dimaksudkan sebagai sebuah realitas mengenai "keaslian" gagrag Tegalan yang absolut. Penanda kebaruan tersebut terlahir dari proses interaktivitas dalam performativitas $\mathrm{Ki}$ Enthus Susmono, melalui strategi representasi seni postmodern sebagai cara bermain-main dengan tanda untuk membongkar rezim kebenaran yang dianggap sebagai keabsolutan dalam gagrag pedalangan, telah berhasil menjadi titik pertemuan 
kultur-kultur baru yang melahirkan sebuah realitas sebagai kebaruan gagrag dalam dunia seni pedalangan.

\section{Kepustakaan}

\section{a. Acuan}

Andrieu, Sarah Anaïs. 2017. Raga Kayu Jiwa Manusia Wayang Golek Sunda. Jakarta: Gramedia.

Austin, J.L. 1962. How to Do Things with Words. Cambridge, Massachusetts: Harvard University Press.

Boonstra, Sadiah Nynke. 2014. "Changing Wayang Scenes: Heritage Formation and Wayang Performance Practice in Colonial and Postcolonial Indonesia”. [Disertasi]. Vrije Universiteit Amsterdam.

Cahya. 2014. "Garap Pertunjukan Wayang Golek Sunda: Sajian Tjetjep Supriadi, Dede Amung Sutarya, dan Asep Sunandar Sunarya”. [Disertasi]. Yogyakarta: Sekolah Pengkajian Seni Pertunjukan dan Seni Rupa Universitas Gadjah Mada Yogyakarta.

Claeys, Sarah. 2007. "How to Do Things With Butler: An Inquiry The Origin Citattion and Application of Judith Butler's Theory of Performativity". Faculteit Letteren en Wijsbegeerte, Universiteit Gent.

Derrida. [1972] 1988. "Signature, Event, Context," in Limited Inc., translated by Samuel Weber and Jeffrey Mehlman, 1-24. Evanston, IL: Northwestern University Press.

Emerson, Kathryn. 2016. “Transforming Wayang for Contemporary Audiences: Dramatic Expression in Purbo Asmoro's Style 19892015”. [Disertasi]. Universiteit Leiden.

Felman, Shoshana. 2003. The Scandal of The Speaking Body: Don Juan with J.L. Austin, or Seduction in Two Languages. California: Stanford University Press.

Groenendael, Victoria M.C. 1987. Dalang Dibalik Wayang. Jakarta: Pustaka Utama Grafiti.

Pemberton, John. 2003. "Jawa" on The Subject of "Java". Yogyakarta: Mata Bangsa.

Poerwadarminta, WJS. 1939. Baoesastra Djawa. Batavia: Percetakan J.B. Wolters.

Shiraishi, Saya Sasaki. 2009. Pahlawan-Pahlawan Belia. Jakarta: Nalar.
Schechner, Ricard. 2013. Performance Studies: An Introduction (Third Edition). New York: Routledge.

Sugiharto, I. Bambang. 2017. Postmodernisme, Tantangan Bagi Filsafat. Yogyakarta: Kanisisus.

Sukistono, Dewanto. 2013. "Wayang Golek

Menak Yogyakarta, Bentuk dan Struktur Pertunjukannya”. [Disertasi]. Yogyakarta: Sekolah Pascasarjana Prodi Pengkajian Seni Pertunjukan dan Seni Rupa, Universitas Gadjah Mada Yogyakarta.

Sumarsam. 2018. Memaknai Wayang dan Gamelan Temu Silang Jawa, Islam dan Global. Yogyakarta: Gading.

Sunardi, St. 2012. Lagune Cara Landa kok Tembunge basa Jawa: Perspektif Pascakolonial dalam Kajian Religi, Vodka dan Birahi Seorang "Nabi": Esai-esai Seni dan Estetika. Yogyakarta: Jalasutra.

Susmono, Enthus. 2016. Pakeliran Wayang Gagrak Tegal: Jati Kusuma. Prambanan: Rumah Empu.

Prambanan: Rumah Empu.

Vulic, Ana. 2012. "From a Misfire to an Open

Future: Repetition, Performativity, and The Promise of The Metaphor". Jurnal Forum: University of Edinburgh Postgraduate Journal of Culture and the Arts.

Wheale, Nigel. 1995. The Postmodern Arts: an introductory reader. New York: Routledge.

\section{b. Audio-Visual}

Ki Enthus Susmono. Lakon Kembang Wijaya Kusuma, Wayang Golek Gagrag Tegalan dalam rangka penutupan Hari Wayang Dunia 2016 ISI Surakarta. Sumber: youtube [10 April 2018].

Ki Enthus Susmono. Lakon Cupu Manik Asvagina, Wayang Kulit Pentas Rutin Jum'at Kliwonan, Taman Budaya Jawa Tengah, Surakarta 17 Maret 2011. Sumber: Pusat Audio Visual Dinas Kebudayaan dan Pariwisata, Taman Budaya Jawa Tengah (koleksi pribadi).

Ki Enthus Susmono. Lakon Sugriwa-Subali, Wayang Kulit tayangan televisi Indosiar tahun 1997. Sumber: youtube [10 April 2018].

Ki Enthus Susmono. Lakon Surgiwa-Subali, Wayang Kulit tayangan televisi Indosiar tahun 
2001. Sumber: youtube [10 April 2018].

Ki Enthus Susmono. Lakon Pandhawa Gugat, Wayang Kulit ditayangkan di TVRI Jatim (TT). Sumber: youtube [10 April 2018].

Ki Enthus Susmono. Lakon Dewa Ruci, Wayang Kulit Puppet Festival 2009, Denpasar Bali. Sumber: youtube [10 April 2018].

Ki Enthus Susmono. Lakon Pandhawa Bangkit, Wayang Kulit Harlah PKB ke 15, Jakarta 2013. Sumber: youtube [12 April 2018].
Ki Enthus Susmono. Lakon Dewa Ruci, "Wayang SUPERSTAR Dewa Ruci Poppenspeler Ki Enthus Susmono met Gamelan Orkest", tahun 2009. Sumber: Facebook Anggit Rianansyah, diunggah pada 18 Maret 2019, 00.36 WIB. [diunduh pada 19 Maret 2019]. Ki Enthus Susmono. Lakon Resi Adam Awal-Adam Akhir, Wayang Golek Gagrag Tegalan, pesta sedekah laut Pelabuhan Tegal, Desember 2017. Sumber: youtube [10 April 2018]. 